\title{
BASIC RADIO PROPAGATION PREDICTIONS FOR JUNE 1945
}

THREE MONTHS IN ADVANCE

\author{
ISSUED
}

MARCH 1945

PREPARED BY INTERSERVICE RADIO PROPAGATION LABORATORY National Bureau of Standards Washington 25, D. C. 
"This document contains information affecting the national defense of the United States within the meaning of the Espionage Act, 50 U. S. C., 31 and 32. Its transmission or the revelation of its contents in any manner to an unautborized person is probibited by law." 
WASHINGTON, D. C.

Organized Under Joint U. S. Communications Board

\section{BASIC RADIO PROPAGATION PREDICTIONS FOR JUNE 1945 THREE MONTHS IN ADVANCE}

The nonthly reports of the IRIL-D series are distributed to the Army as the TB 11-49y series, by the Adjutant General; to the Navy as the UNC-13-1 series, by the Registered Publications Section, Division of Naral Communications; and to others by the 1RPL.
The IRPL-D series reports are monthly supplements to the IRPL Radio Propagation Handbook, Part 1, issued by the Arny as TM 11-499 and by the Nary as DNC-13-1, and is required in order to make practical application of the basic I Iandbook.

\section{CONTENTS}

1. Terminology

II. World-wide prediction charts and their uses Page 2

World map showing zones covered by predicted charts, and auroral zones_-_ Fig. 1

$F^{*}$-zero-muf, in Me, $W$ zone, predicted for June $1945 \ldots$

Fo-4000-muf, in Mc, IV zone, predicted for June $1945_{\ldots}$

F2-zero-muf, in $\mathbf{I}^{\circ}, I$ zone, predicted for Jume 1945

F2-4000-muf, in Me, I zone, predicted for June 1945_._._._._._._. Fig. 8 F2-zero-muf, in Mc, $E$ zone, predicted for . June 1945_..... Fig. 9 Fo-4000-muf, in $\mathrm{Mc}, E$ zone, predicted tor sulse 194.

$E$ laser 2000-muf, in Mc, predicted for June 1945

Fig. 11

Median $f E s$, in Me, predicted for June 1945_.___. Fig. 12

Percentage of time occurrence for $E s$ in excess of $15 \mathrm{Mc}$, predicted for June $1945 \mathrm{Fig} .15$

III. Determination of great-circle distances, bearings, location of transmission control points, solar zenith angles_________ Page 2

Great-circle chart, centered on equator, with small circles indicating distances in kilometers

Diagram of transmission path auxiliary to explanation of use of distance-bearing nomogram, figure 4.
III. Detrinination, ete-Continued.

Nomogram for obtaining great-circle distances, bearings, latitude and longitude of transmission control points, solar zenith angles. Conversion sale for various distance units._._. Fig. 4

IV. Calculation of maximum usuable frequencies and optimum working frequencies___ lage 3

Nomograms for transforming $F^{\text {ra }}$-zero lutuf and F2-4000-muf to equivalent maximum usable frequencies at intermediate transmission distances; conversion scale for obtaining optimum working frequencies_________. Fig. 13

Nomogram for transforming $L$-layer 2000-muf to equivalent maximum usable frequencies and optimum working frequencies due to combined effect of $E$ layer and $F 1$ layer at otler transmission distances

V. Absorption, distance range, and lowest useful high frequeney________._._. Page 4

Absorption index chart (excluding anroral absorption ) for June_________ Fig. 16

VI. Sampln muf and owf calculations________ Page 5 For short path (under $4000 \mathrm{~km}$ ) page 5 , table 1 , page 6 , ant Fig. 17 For long path (over $4000 \mathrm{~km}$ ) page 5 , table 2, pagr (;, and Fig. 18 


\section{TERMINOLOGY}

The following symbols are used, as recommended by the International Radio Propagation Conference held in Washington, D. C., $17 \mathrm{April}$ to 5 May 1944.

$$
\begin{array}{r}
f^{\circ} F 2=\text { ordinary-wave critical frequency } \\
\text { for the } F 2 \text { layer. The term } \\
\text { night } F \text { layer will no longer be } \\
\text { used. The term } F 2 \text { layer is } \\
\text { now used for the night } F \text { as } \\
\text { well as the daytime } F 2 \text { layer. } \\
f^{x} F 2=\text { extraordinary-wave critical fre- } \\
\text { quency for the } F 2 \text { layer. } \\
E s=\text { sporadic, or abnormal } E \text {. }
\end{array}
$$

$$
f E s=\underset{\text { highest frequency of } E s \text { reflec- }}{\text { tions. }} \text {. }
$$

muf or MUF = maximum usable frequency.

owf or OWF = optimum working frequency. 4000 -muf chart $=$ contour chart of muf for 4000 kilometer paths.

2000 muf chart $=$ contour chart of muf for 2000 kilometer paths.

Zero-muf chart $=$ contour chart of vertical-incidence critical frequency, extraordinary wave.

$K=$ absorption index (ratio of actual absorption to absorption at the subsolar point).

Note.-The designation $F_{2}$ has been replaced by $F_{2}$.

\section{WORLD-WIDE PREDICTION CHARTS AND THEIR USES}

The charts, figures 5 to 11 , present world-wide predictions of monthly average maximum usable frequencies for June 1945. Conditions may be markedly different on disturbed days, especially in or near the auroral zones, shown on the map of figure 1. The method of prediction is discussed in the IRPL Radio Propagation Handbook, Part 1, War Dept. TM 11-499, Navy Dept. DNC-13-1, p. 52, 53.

Ionosphere characteristics are roughly similar for locations of equal latitude, but there is also a considerable variation with longitude, especially in the case of the $F 2$ layer. This "longitude effect" seems to be related to geomagnetic latitude. Attention was first called to this effect in the report "Radio Propagation Conditions" issued 10 Sept. 1943 ; it was brought into general operational use in the next issue (14 Oct. 1943).

The longitude effect in the $F 2$ layer is taken care of by providing world charts for three zones, in each of which the ionosphere characteristics are independent of longitude, for practical purposes. These zones are indicated on the world map, figure 1.
Two F2 charts are provided for each zone, one of which, the "zero-muf chart," shows the verticalincidence muf, or the critical frequency for the extraordinary wave, and the other, the "4000-muf chart," shows the muf for a transmission distance of $4000 \mathrm{~km}$. Do not confuse the zero-muf charts with the $f^{\circ} \mathrm{F} 2$ charts appearing in the previous IRPL reports "Radio Propagation Conditions." (Values of $F 2$ zero-muf exceed those of $f^{\circ} F 2$ for the same location and local time by an amount approximately equal to half the gyrofrequency for the location. See IRPL Radio Propagation Handbook, Part 1 (War Dept. TM-11-499 and Navy Dept. DNC-13-1), pp. 18, 19, 28, and fig. 9.)

The longitude variation is operationally negligible in the case of the normal $E$ layer and therefore only one $E$-layer chart is provided.

The variation of $f E s$ with geomagnetic latitude seems to be well-marked and important, but there are, as yet, insufficient correlated data to permit an estimate of this variation; the $f E s$ charts furnished here are therefore of a far lower degree of precision than the other charts.

\section{DETERMINATION OF GREAT-CIRCLE DISTANCES, BEARINGS, LOCATION OF TRANSMISSION CONTROL POINTS, SOLAR ZENITH ANGLES}

1. 'The first step in any radio propagation calculation is the determination of the transmission path, which is the great-circle distance between transmitting and receiving stations. Use the world map, figure 1, and the great-circle chart, figure 2 , for this purpose, as follows:

a. Place a piece of transparent paper over the map, figure 1 , and draw upon it a convenient reference latitude line, the locations of the transmitting and receiving stations, and the meridian whose local times are to be used as the times for calculation. b. Place this transparency over the chart, figure 2 , and, keeping the reference line at the proper latitude, slide the transparency horizontally until the terminal points marked on it either fall on the same great-circle curve, or fall the same proportional distance between adjacent great-circle curves. Draw in the path.

c. Locate the midpoint of the path, for paths under $4000 \mathrm{~km}$, or the "control points," $2000 \mathrm{~km}$ from either end of the path, for paths greater than $4000 \mathrm{~km}$, and use for this purpose the small circles of figure 2 . 
d. Place the transparency over the predicted chart at the proper latitude and local time, and read the ralues of muf off the chart, as directed in section IV.

2. Great-circle distances, bearings, location of midpoints, or other "control points" $2000 \mathrm{~km}$ in from the ends of the transmission path, as well as solar zenith angles, may be readily obtained from the nomogram. figure 4 .

Referring to the auxiliary diagram, figure 3 , let $Z$ and $S$ be the locations of transmitting and receiving stations: then, use the nomogram, figure 4 , as follows:

a. To obtain the great-circle distance ZS:

(1) Draw slant line from (lat. of $Z$ - lat. of $S$ ). measured up from bottom of left scale to (lat. of $Z$ + lat. of $S^{\prime}$ ), measured down from top of right scale.

(2) From (long. of $S$-long. of $Z$ ) on bottom scale, measured from left to right, draw vertical line to the slant line obtained in (1).

(3) From the intersection, draw a horizontal line to the left scale. This gives $Z S$ in degrees.

(4) Convert the distance $Z S$ to kilometers, statute miles, or nautical miles, by using the scale at the bottom of figure 4.

b. To obtain the bearing angle PZS:

(1) Subtract the distance $Z S$ (in degrees) from $90^{\circ}$ to get $h$.

(2) Draw slant line from (lat. $Z-h$ ), measured up from bottom on left scale, to (lat. $Z+h$ ). measured down from top on right scale.

(3) From $\left(90^{\circ}\right.$-lat. $\left.S\right)$ on left, measured up from bottom on left scale, draw horizontal line until it intersects previous slant line.

(4) From the intersection, draw a vertical line to the bottom scale, which gives the bearing angle $P Z S$, in degrees.

c. To obtain the bearing angle PSZ:

(1) Repeat steps (1), (2), (3) and (4) in b, interchanging $Z$ and $S$ in all computations. The result obtained in the interior angle $P S Z$, in degrees.
(2) The bearing angle $P S Z$ is $360^{\circ}$ minus the result obtained in (1) (since bearings are customarily given clockwise from due north).

d. To obtain latitude of $Q$ (mid, or other, point of path) :

(1) Obtain $Z Q$ in degrees. If $Q$ is the midpoint of the path, $Z Q$ will be equal to one-half $Z, S$. If $Q$ is one of the $2000-\mathrm{km}$ "control points." $Z Q$ will be approximately $18^{\circ}$, or $Z, S-18^{\circ}$.

(2) Subtract $Z Q$ from $90^{\circ}$ to get $h^{\prime}$.

(3) Draw slant line from (lat. $\left.Z-h^{\prime}\right)$, measured up from the bottom of left scale, to (lat. $\left.Z+h^{\prime}\right)$, measured down from top on right scale.

(4) From bearing angle $P Z S$, measured to right on bottom scale, lraw vertical line to the above slant line.

(5) From this intersection, draw horizontal line to left scale.

(6) Subtract the reading given from $90^{\circ}$ to give latitude of $Q$ in degrees.

e. To obtain longitude difference, $t^{\prime}$, between Z and $Q$ :

(1) Draw straight line (lat. $Z$-lat. Q), measured up from bottom on left-hand scale, to (lat. $Z+$ lat. Q), measured down from top on righthand scale.

(2) From the left side, at $Z Q$, in degrees, draw a horizontal line to the above slant line.

(3) From the intersection, drop a vertical line to bottom scale to get $t^{\prime}$ in degrees.

f. To obtain solar zenith angle, $\psi$, at a given place:

(1) Let the declination of the sun be $d$, and let $Z$ be the place under consideration.

(2) Draw straight line from (lat. $Z-d$ ), measured up from bottom on left scale, to $($ lat $Z+d)$, measured down on right seale.

(3) From [ (12-local time of $Z$, in hours $) \times 15]$ degrees, on bottom seale, measured from left to right, draw a vertical line to the slant line above.

(4) From this intersection, draw a horizontal line to the left scale. This gives $\psi$, in degrees.

\section{CALCULATION OF MAXIMUM USABLE FREQUENCIES AND OPTIMUM WORKING FREQUENCIES}

\section{PROCEDURE FOR DETERMINATION OF MUF OR OWF FOR TRANSMISSION DISTANCES UNDER 4000 KM}

Radio propagation over distances up to 4000 $\mathrm{km}$ is usually determined by ionospheric conditions at the midpoint of the great-circle path between transmitting and receiving station.

For a path $4000 \mathrm{~km}$ in length, read the predicted monthly average $F 2$ muf directly off the 4000 -muf charts furnished, at the latitude and local time of the midpoint of the path. For a path $2000 \mathrm{~km}$ in length read the predicted monthly average $E$-layer muf directly off the $E$-layer 2000-muf chart. Use the following procedure for other distances:

a. Locate the midpoint of the transmission path. (Methods for doing this are given in the precedin $\underline{\text { section of this report.) }}$

b. Read the values of $F 2$-zero-muf, $F \cdot 2-4000$-muf, and $E$-layer 2000-muf for the midpoint of the path 
at the local time for this midpoint. Be sure to choose the $F 2$ charts for the geographical zone in which the midpoint lies.

c. Place a straightedge betreen the values of F2-zero-muf and F2-4000-muf at the left- and right-hand sides, respectively, of the grid nomogram, figure 13, and read the value of the muf for the actual path length at the intersection point of the straightedge with the appropriate rertical distance line.

d. The optimum working frequency (owf) is 85 percent of the muf, to allow a margin of safety for day-to-day variations; to determine the owf, use the auxiliary scale at the right of the grid nomogram of figure 13.

e. Place a straightedge between the value of the E-layer 2000-muf located on the left-hand scale of the nomogram, figure 14 , and the value of the path length on the right-hand scale, and read the combined $E$ - and F1-layer muf or owf for that path length, off the central scale. (The characteristics of the $E$ layer and of the $F 1$ layer are sufficiently related that, for most practical purposes, they may be combined in this manner.)

f. Compare the values of muf or owf obtained by operations c to $\mathrm{e}$. The higher of the two values thus determined is the muf or owf for the path.

\section{PROCEDURE FOR DETERMINATION OF MUF OR OWF FOR TRANSMISSION DISTANCES GREATER THAN 4000 KM}

The complexities of long-distance radio propagation are such that the simple multihop $E^{\prime}$ or $F 2$ layer calculations do not give accurate results. The following procedure will give results which are operationally satisfactory; the theory involved is outside the scope of this report.

a. Locate the two "control points" $2000 \mathrm{~km}$ from the ends of the great-circle distance between transmitting and receiving stations. For very long paths both the "short route" (minor arc of the rreat-circle path) and the "long route" (major" are) need to be considered.

b. Read the value of the $F 2-4000-m u f$, at the local time for each point, at these points, being sure to choose the appropriate zone for each point.

c. Compare these two muf values. The lower of the two is the muf for the transmission path under consideration. Calculate the owf ( $85 \%$ of the muf) for the path, by means of the auxiliary muf-owf scale of figure 13 .

t. Then one of the control points lies in a region where the $E-2000$-muf is greater than the $F 2-4000$-muf. read the $E-2000$ mut at an $E$-layer control point $1000 \mathrm{~km}$ from the end of the path, instead of the F2-4000-muf, as in step b. Use the E-2000-muf in step c, instead of the F2-4000-muf.

\section{PROCEDURE FOR DETERMINATION OF ES TRANSMISSION}

Sporadic-E $(E s)$ propagation plays an important part in transmission over paths in some parts of the world and at certain times; it may often produce regular transmission at times when regnlar F2-layer propagation would not. Es data are not yet sufficient to permit accurate calculations of such propagation, but the charts of figures 12 and 15 are given as a guide to $E s$ occurrence. Until such time as more definite information is available, the following procedure should be used to find the prevalence of Es propagation over long paths.

a. For paths over $4000 \mathrm{~km}$ long:

(1) Place the great-circle path transparency, prepared in section III, 1 , over the median f $E$ s chart, figure 12.

(2) Scale $f E_{s}$ at each $E$-layer eontrol point (1000 km from each end of the path), multiply by 5 and subtract $4 . M_{c}$. The result is Es-owt.

(3) Plot as the owf for each control point the higher of the two values, the F2-4000-owf and the Es-owf.

b. For use over paths of lengths up to $4000 \mathrm{~km}$, scale the Es at the midpoint of the path. multiply by 5 and substract 4 Mc, and use the resultant frequency instead of the $E-2000-m u f$ in the nomogram of figure 14 .

\section{Y. ABSORPTION, DISTANCE RANGE, AND LOWEST USEFUL HIGH FREQUENCY}

The determination of absorption, distance range, and lowest useful high frequency is discussed at length in IRPL Radio Propagation Handbook, Part 1, p. 69-97 (War Dept. 'T'M 11-499, Navy Dept. DNC-13-1), and formulas, graphs, and nomograms for calculation are given there. For tonvenience in estimating absorption (exclusive of auroral absorption) over a path, the absorption index (or $h^{r}$ ) cliart, figure 16, is presented. By siperposing the transparency with the great-circle path, prepared as in section III. 1, the relation of the path to the sun's zenith angle is readily seen (the sumrise-sunset line corresponds to an absorption index $=0.14$ ).

The absorption is erratic and considerably greater in and near the auroral zones. shown on the map of figure 1; paths passing through or near these zones are subject at times to severe disturbances. 


\section{SAMPLE MUF AND OWF CALCULATIONS}

\section{FOR SHORT PATHS}

Required: The muf and owf for transmission between Washington, D. C. $\left(39.0^{\circ} \mathrm{N}, 77.5^{\circ} \mathrm{W}\right)$ and Miami, Fla. (25.5 N, $\left.80.5^{\circ} \mathrm{WV}\right)$ for average conditions during the month of June 1945.

Solution:

Let the local time used for this problem be GC'T ( $Z$ time or that of $0^{\circ}$ longitude).

The midpoint of the path is at approximately $32.5^{\circ} \mathrm{N}, 79.0^{\circ} \mathrm{W}$, and the transmission path length is approximately $1500 \mathrm{~km}$.

The values of $E$ - and $F 2$-layer muf and owf and also $E s$-owf for alternate hours, GCT, as determined by using the procedure given in section IV, are given in table 1 . The final values are presented graphically in figure 17. In obtaining the combined muf. all layers, the $E s$-owf is used because of the great variability of the muf.

Figure 17 shows that skip will occur, on the average, during the night hours if a frequency as high as $7.0 \mathrm{Mc}$ is used. A frequency as high as 5.0 Mc will not ship, on the average, at any time of day, but its use is not advisable because of (a) the day-to-day variability, causing some probability of skip during the night hours, and (b) ionospheric absorption during the daytime, which is more pronounced at low frequencies.

A satisfactory frequency plan to insure continuous transmission at all times, on a circuit like this, involves the use of two frequencies, one for night and one for day. Figure 17 shows that a night frequency of 4.4 Me used bet ween the hours of 0520 and 1110 GCT, and a day frequency of 9.0 Ilc to be used from 1110 to 0520 . would be satisfactory. The periods of usefulness of these frequencies are shown by the heary dashed line on tigure 17.

Periods of time during which transmission is controlled by either the $E$ layer or $F 2$ layer may be easily recognized by noting the relative proximity of the muf and owf curves of figure 17. Coincidence of the curves indicates control by sporadic- $E$ reflections.

\section{FOR LONG PATHS}

Required: The muf and owf for transmission between Chungking, China $\left(29.4^{\circ} \mathrm{N}, 106.8^{\circ} \mathrm{E}\right)$, and San Francisco, Calif. $\left(37.8^{\circ} \mathrm{N}, 122.4^{\circ} \mathrm{W}\right)$, for average conditions during the month of June 1945.

\section{Solution:}

Let the local time used for this problem be GCT, or that of $0^{\circ}$ longitude.

The path length is approximately $10950 \mathrm{~km}$ and the two $F 2$-layer control points, $A$ and $B$, respectively, are at approximately $43^{\circ} \mathrm{N}, 121^{\circ} \mathrm{E}$ and $49^{\circ}$ $\Gamma, 142^{\circ} \mathrm{W}$. These are respectively in the $E$ zone and the $I$ zone. as shown on the map, figure 1 . The two $E$-layer and Es-control points, $A^{\prime}$ and $B^{\prime}$, respectively. are located at $36^{\circ} \mathrm{N}, 112^{\circ} \mathrm{E}$ and $44^{\circ}$ N. $131^{\circ} \mathrm{W}$. The bearing of San Francisco from Chungking, determined by means of the nomogram of figure 4 , is approximately $36^{\circ}$.

The values of muf and owf over this transmission path. as determined by using the procedure for alternate hours, GCT, are given in table 2. The final values are shown graphically in figure 18.

Figure 18 shows that skip will occur, on the average, during the night hours if a frequency as high as $13 \mathrm{Mc}$ is used, although much higher fre- quencies may be used during a limited portion of the day.

A good practical arrangement to insure continuous transmission at all times is to select three frequencies, in a manner similar to that suggested for the preceding problem. A frequency of 10.2 Me nuy be used from 0640 to $1240 \mathrm{GCT}$, a frequency of $16.0 \mathrm{Mc}$ may be used from 2150 to 0640 , and a frequency of 13.0 Me may be used from 1240 to 1650 .

Relative proximity of the muf and owf curves of figure 18 indicates that the regular $E$ layer does not control transmission at any time. Coincidence of the curves indicates control by sporadic- $E$ ' reflections.

By inspection of the absorption chart, figure 16 , and the noise map (fig. 119 of the IRPL Radio Propagation Handbook, Part 1. War Dept. TM 11-499, Nary Dept. DNC-13-1), it may be ceen that considerations of the lowest useful high frequency over this path may be of considerable importance in selecting frequencies for use, and that in cases of transmission failne on the frequencies here recommended, raising the frequency to a vahe slightly under the muf for the path may be advisable. 
TABLE 1.-Solution of short-path transmission problem

[Washington, D. C. to Miami, Fla., June 1945]

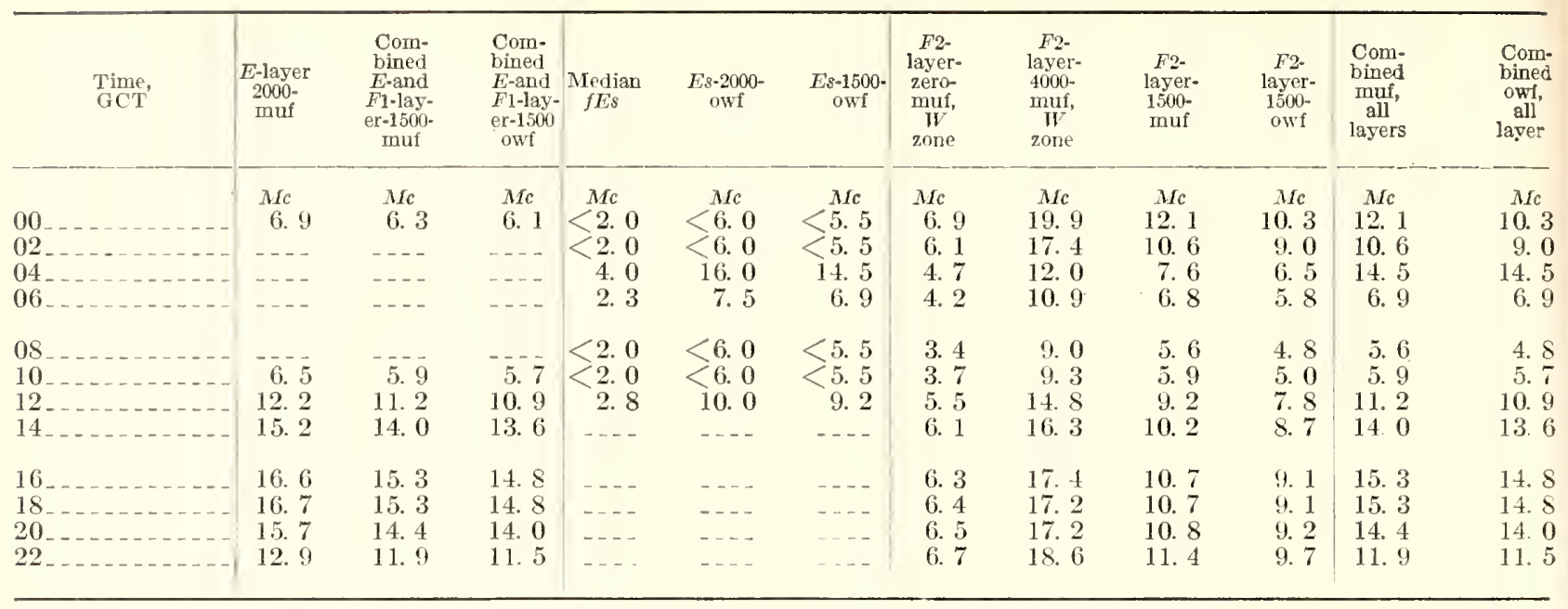

TABLE 2.-Solution of long-path transmission problem

[Chungkins. China, to San Francisco, Calif., June 1945]

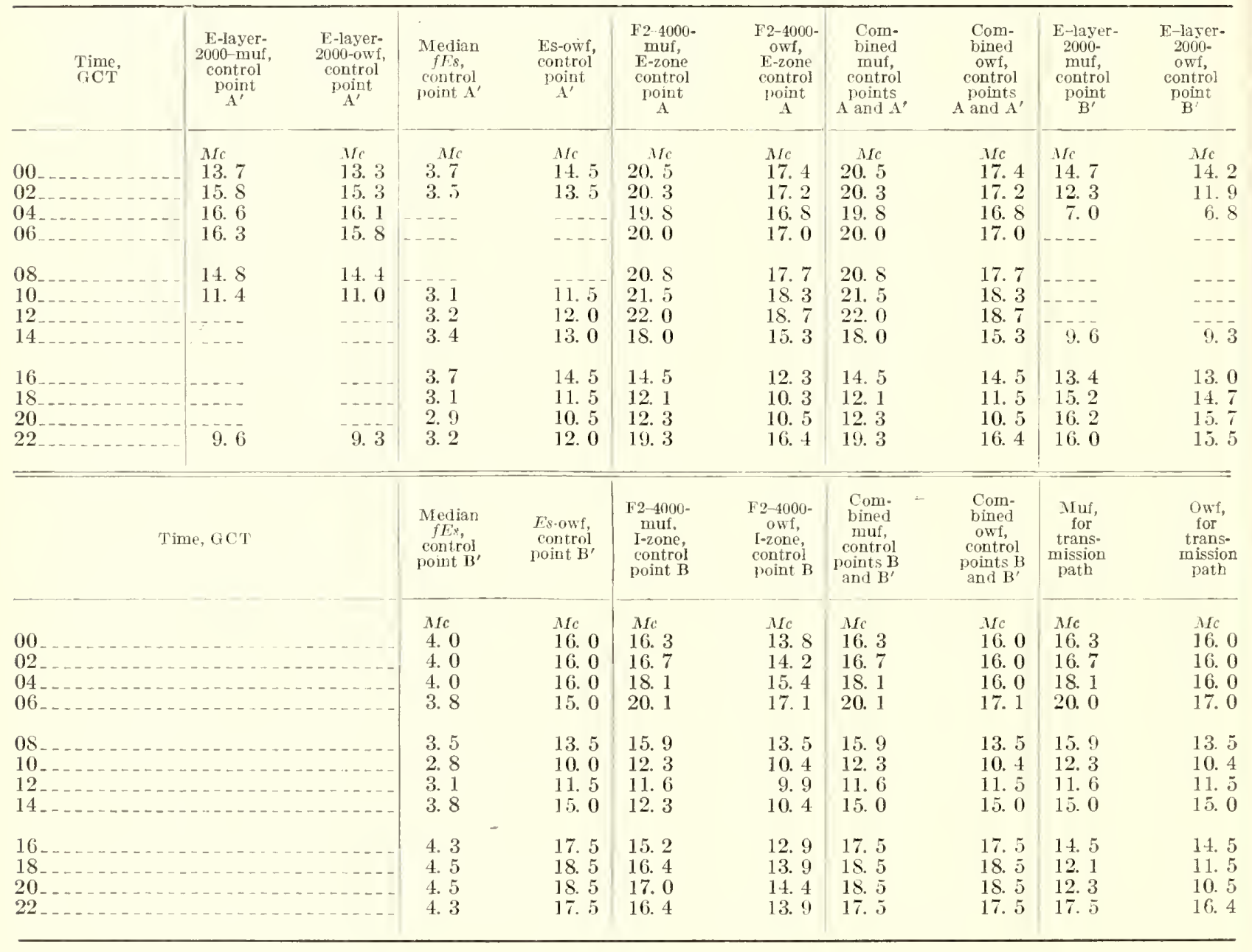





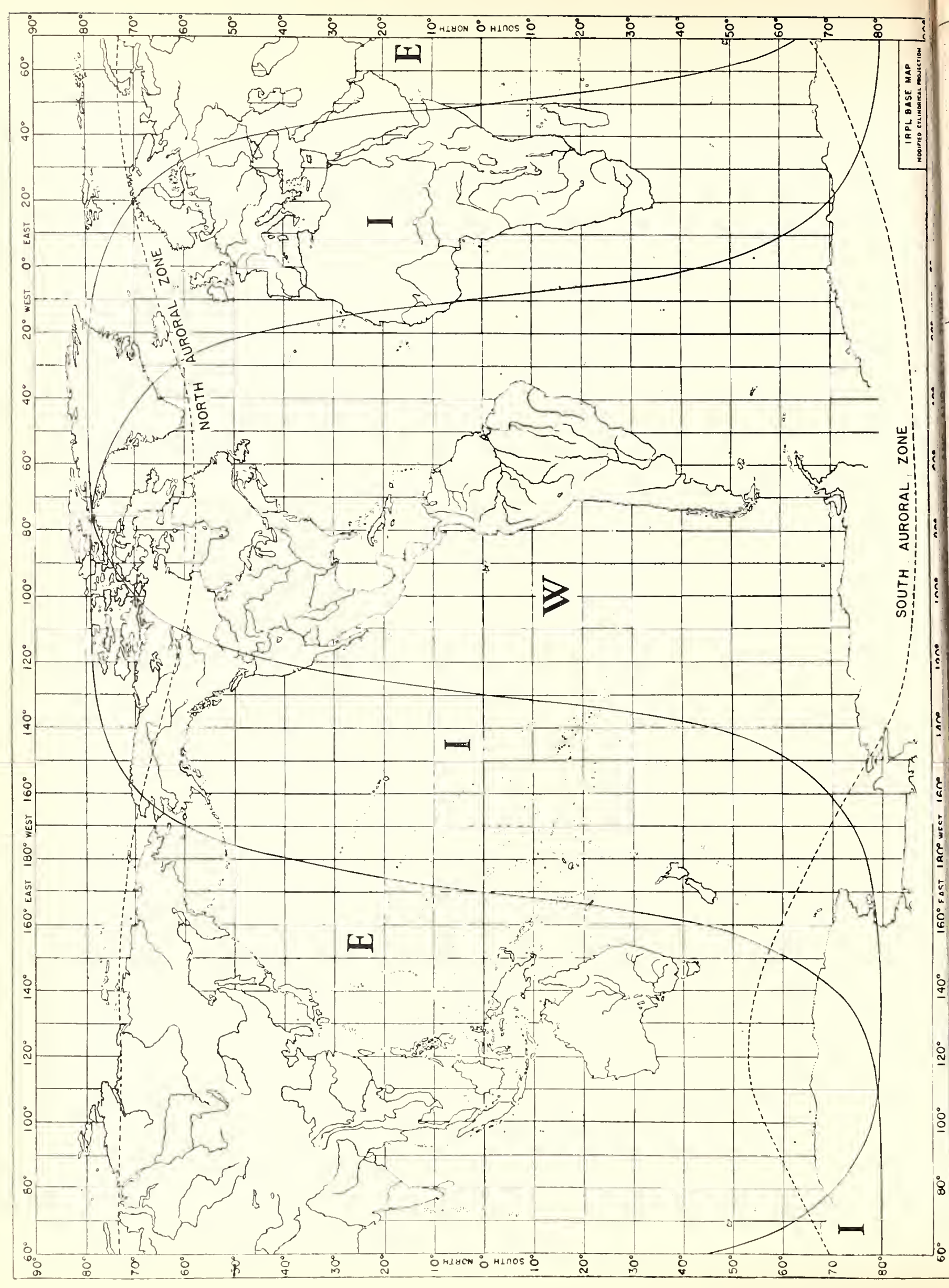




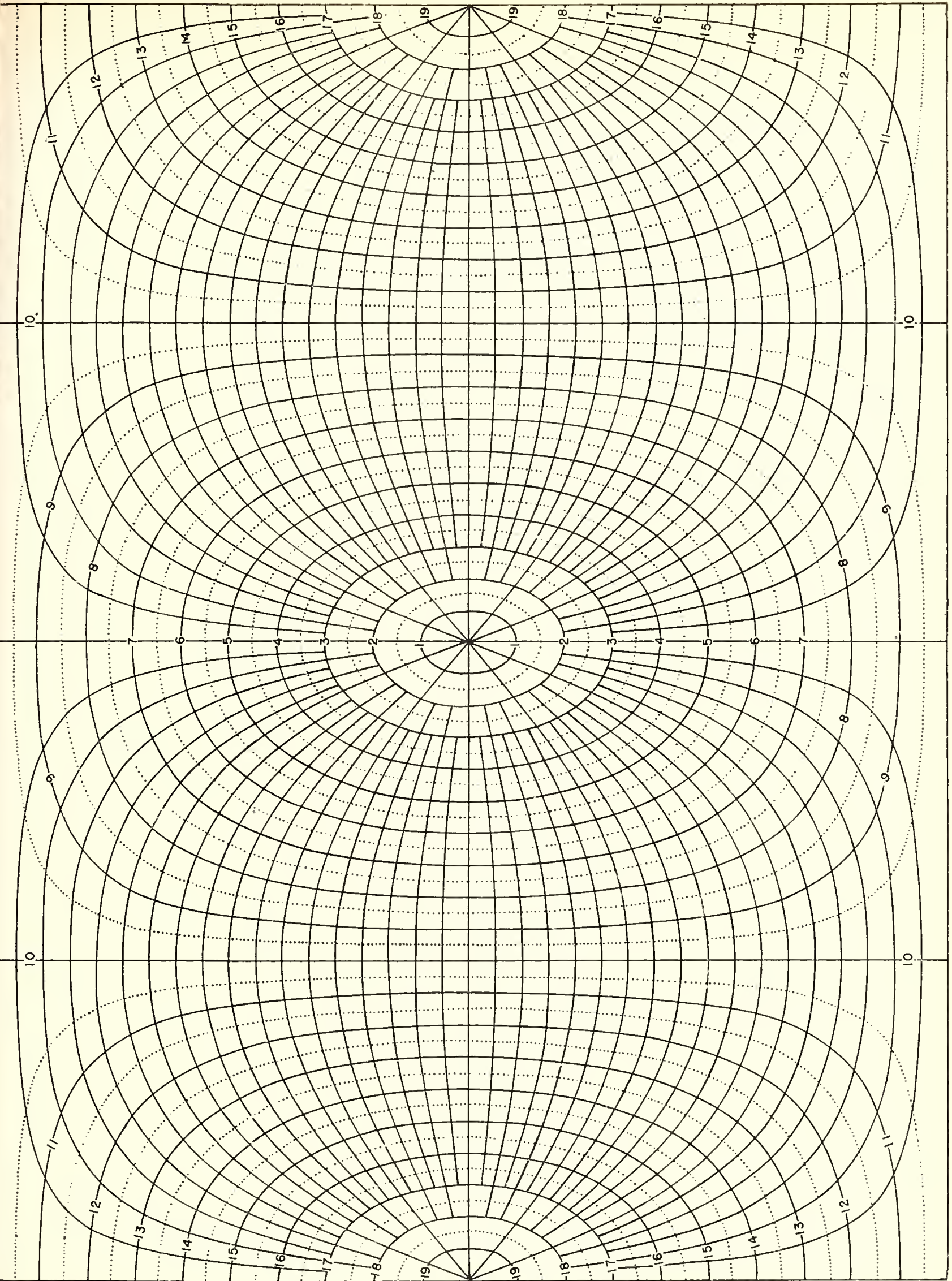

FIG. 2. GREAT CIRCLE CHART, CENTERED ON EQUATOR, WITH SMALL CIRCLES INDICATING DISTANCES IN KILOMETERS. 


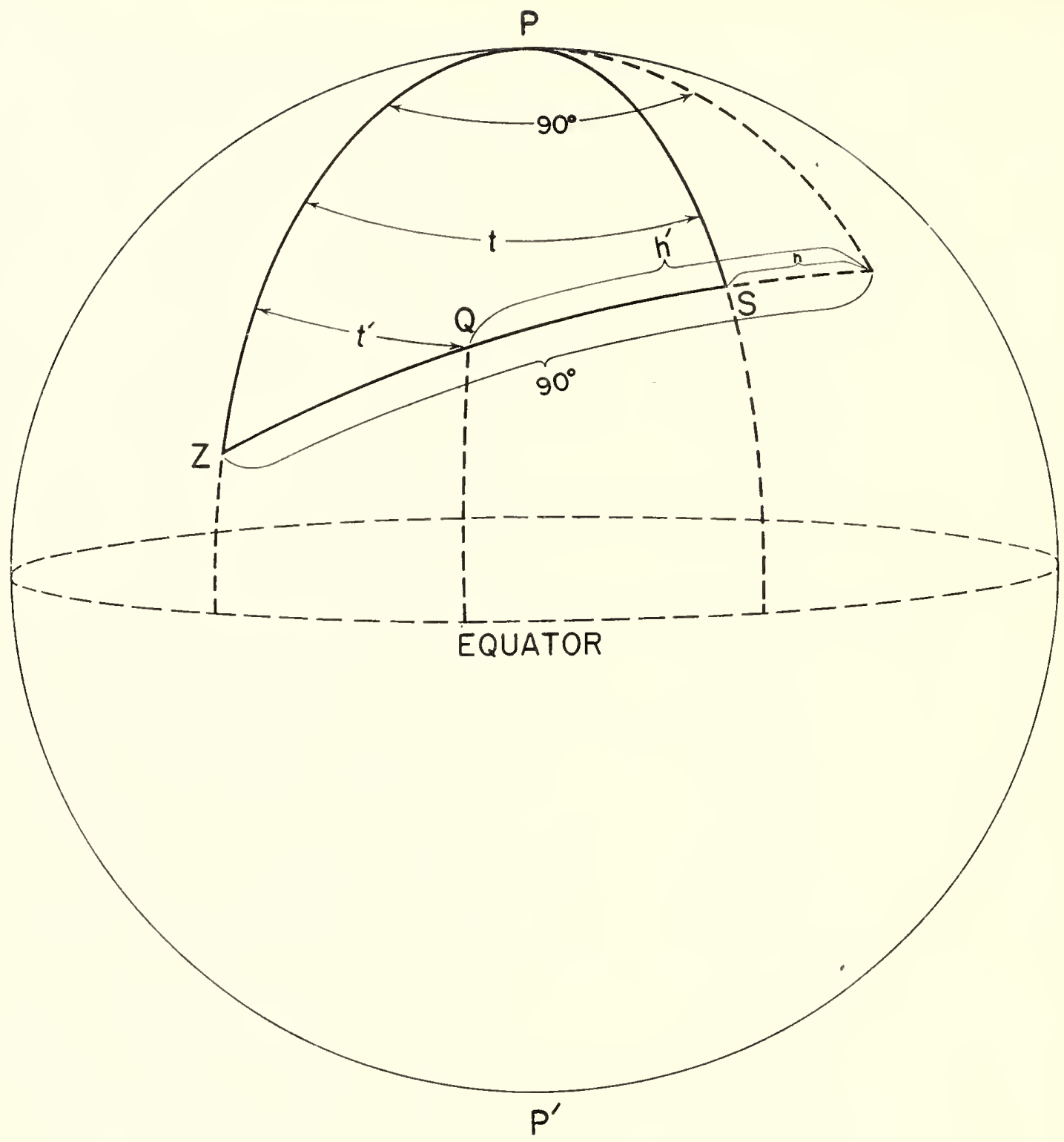

Fig. 3. DIAGRAM OF TRANSMISSION PATH AUXILIARY TO EXPLANATION OF USE OF DISTANCE - BEARING NOMOGRAM, FIG. 4. 
$145^{\circ}$

$135^{\circ}$

$130^{\circ}$

$125^{\circ}$

$120^{\circ}$

11

$110^{\circ}-$

$105^{\circ}$

$100^{\circ}$

$95^{\circ}=$

$90^{\circ}$

$30^{\circ}-$

$75^{\circ}=$

$70^{\circ} \frac{7}{7}$

$65^{\circ}=$

$60^{\circ}=$

$55^{\circ}=$

$50^{\circ}=$

$45^{\circ}$

$40^{\circ}$

$35^{\circ}=$

$30^{\circ}$ 业

$25^{\circ}$.

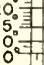

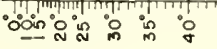

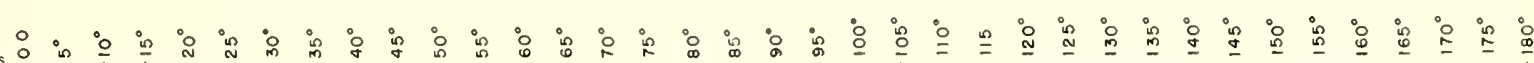

Degres

Thousonds of
Kilometers

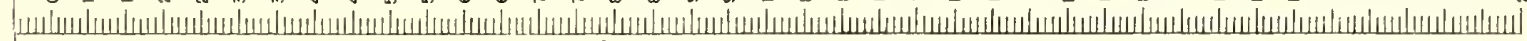

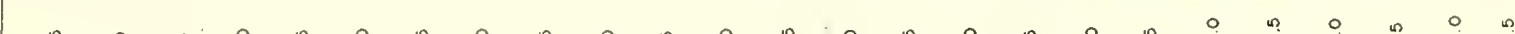
шйس Thousonds of
Noutical Miles

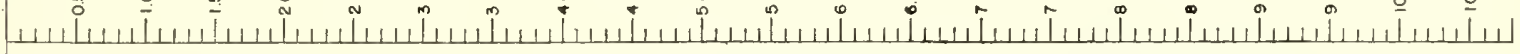

Degres لسل

Fig. 4. NOMOGRAM (AFTER D'OCAGNE) FOR OBTAINING GREAT-CIRCLE DISTANCES, BEARINGS, LATITUDE AND LONGITUDE OF TRANSMISSION CONTROL PONTTS, SOLAR ZENITH ANGLES. CONVERSION SCALE FOR VARIOUS DISTANCE UNITS. 


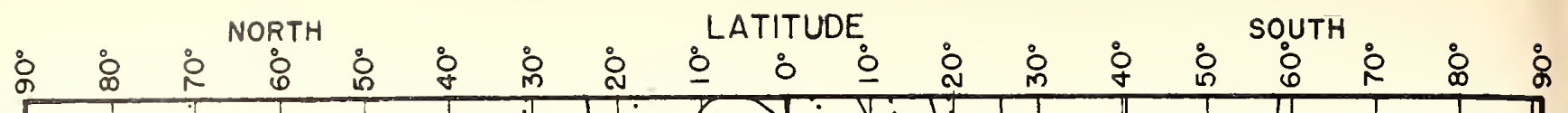

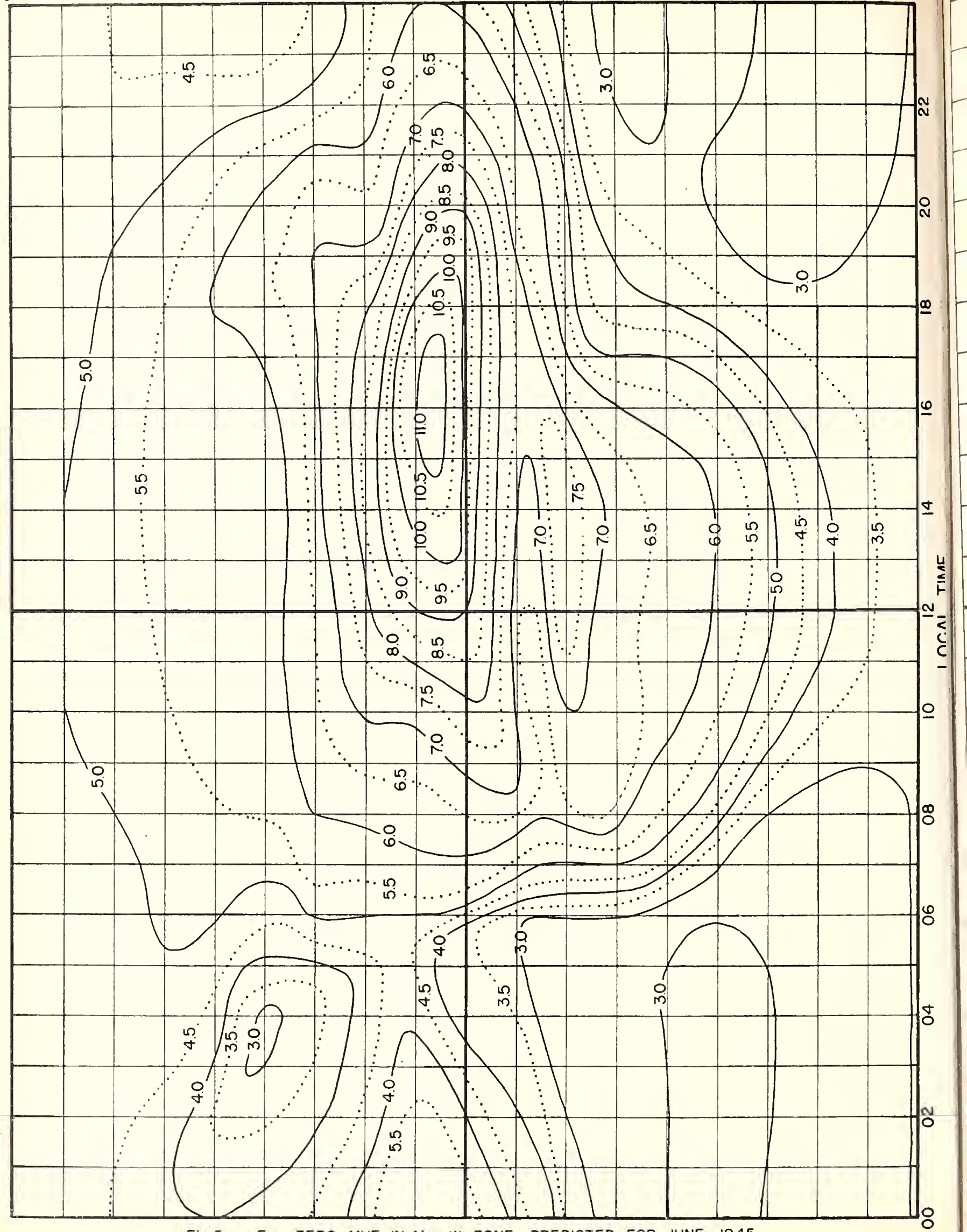

Fig.5. $F_{2}$ ZERO-MUF, IN MC, W ZONE, PREDICTED FOR JUNE, 1945. 


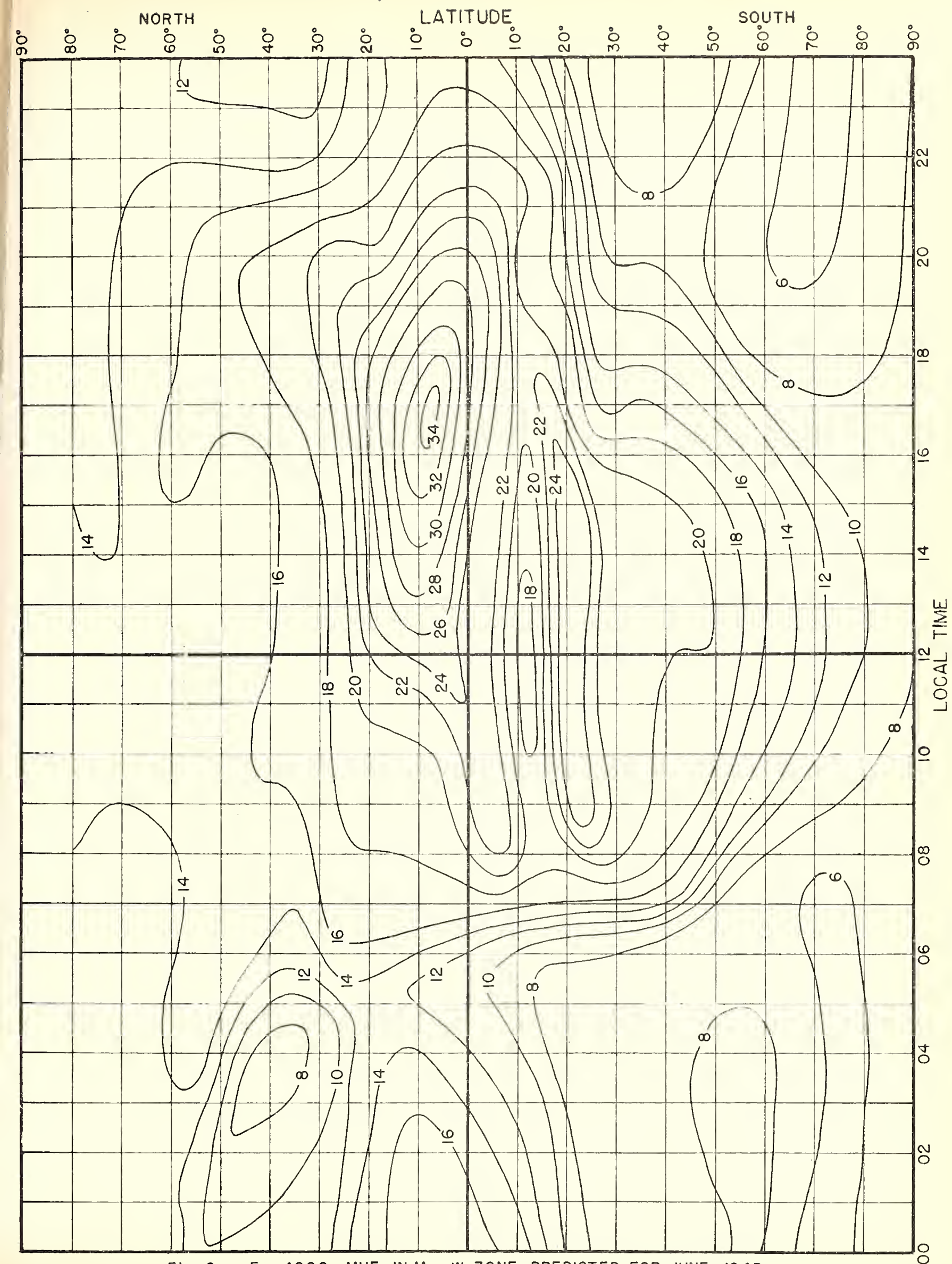

Fig. 6. $F_{2}$ 4000-MUF, IN MC, W ZONE, PREDICTED FOR JUNE, 1945. 


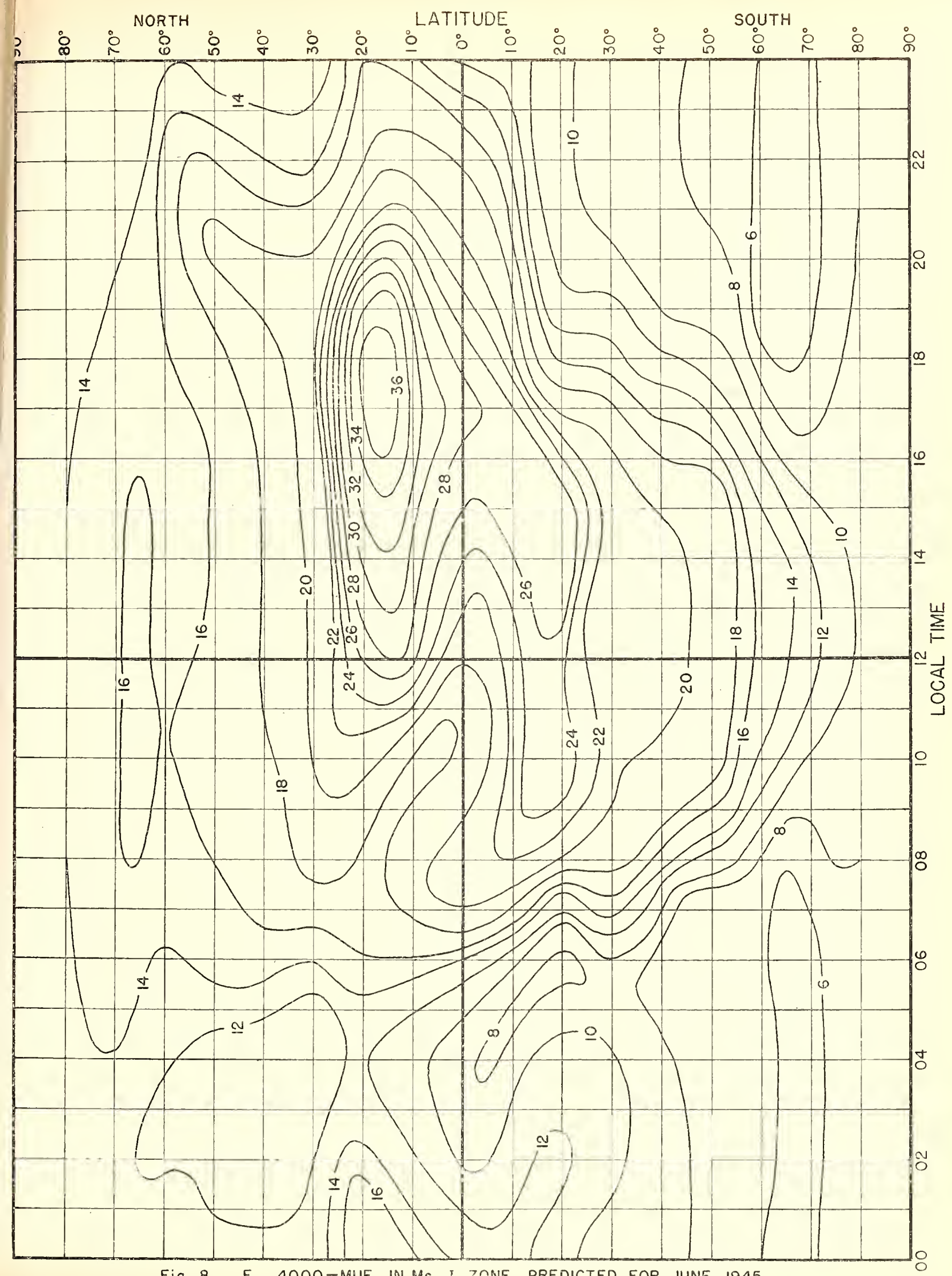

Fig. 8. $F_{2}$ 4000-MUF, IN MC, I ZONE, PREDICTED FOR JUNE, 1945. 


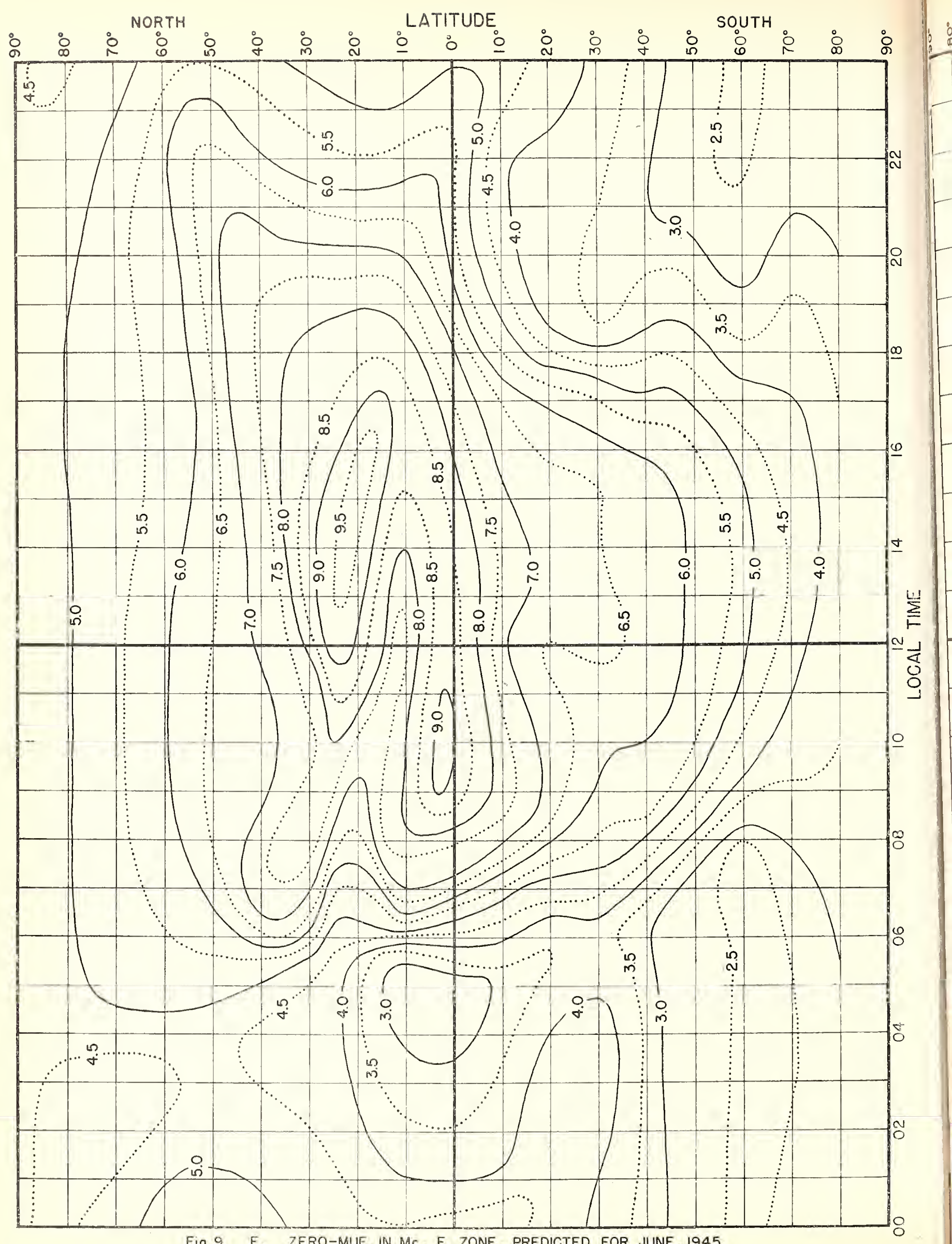

Fig 9. $F_{2}$ ZERO-MUF, IN MC, E ZONE, PREDICTED FOR JUNE, 1945. 


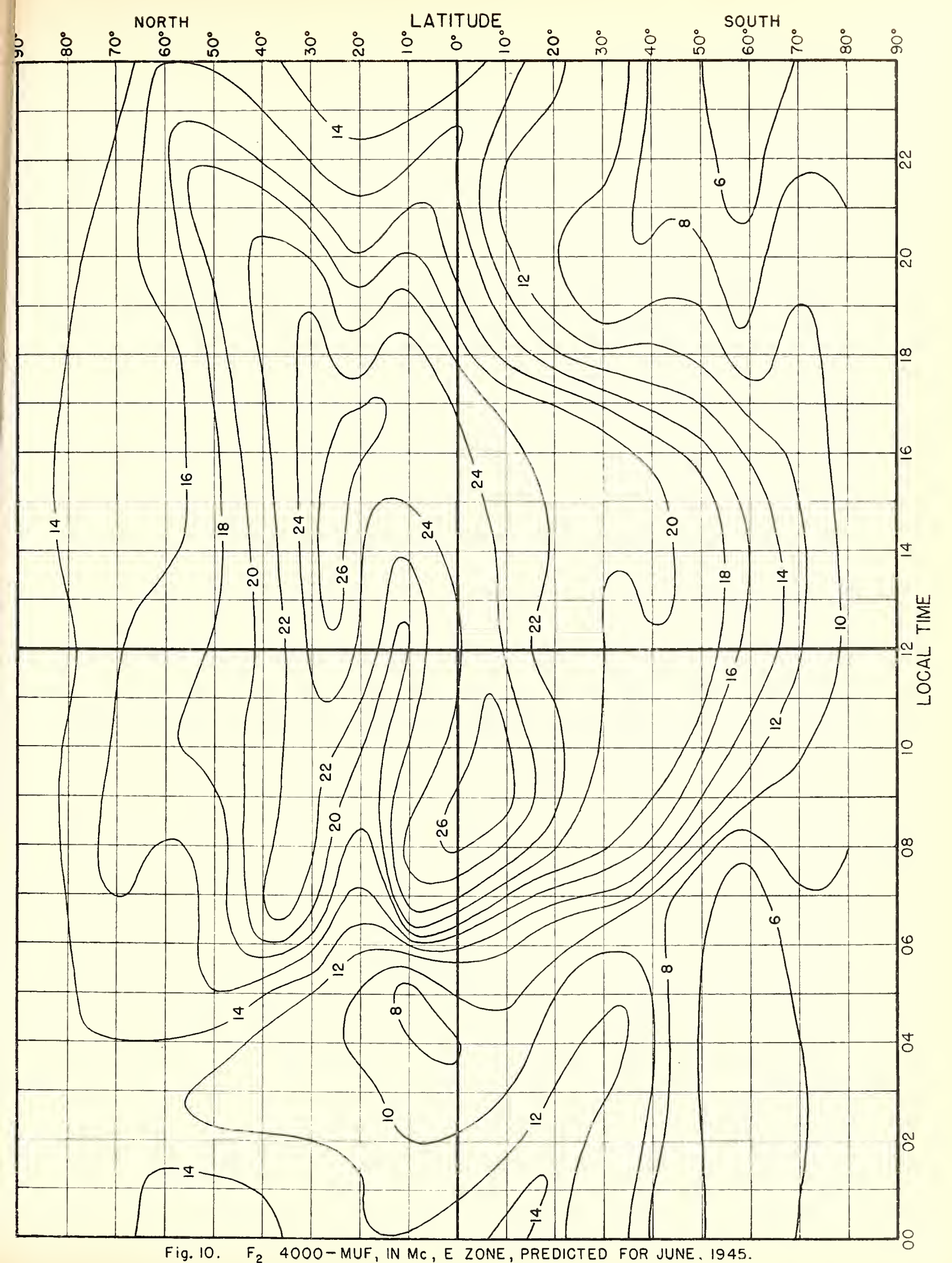




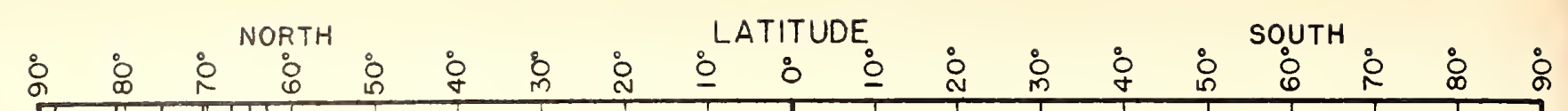

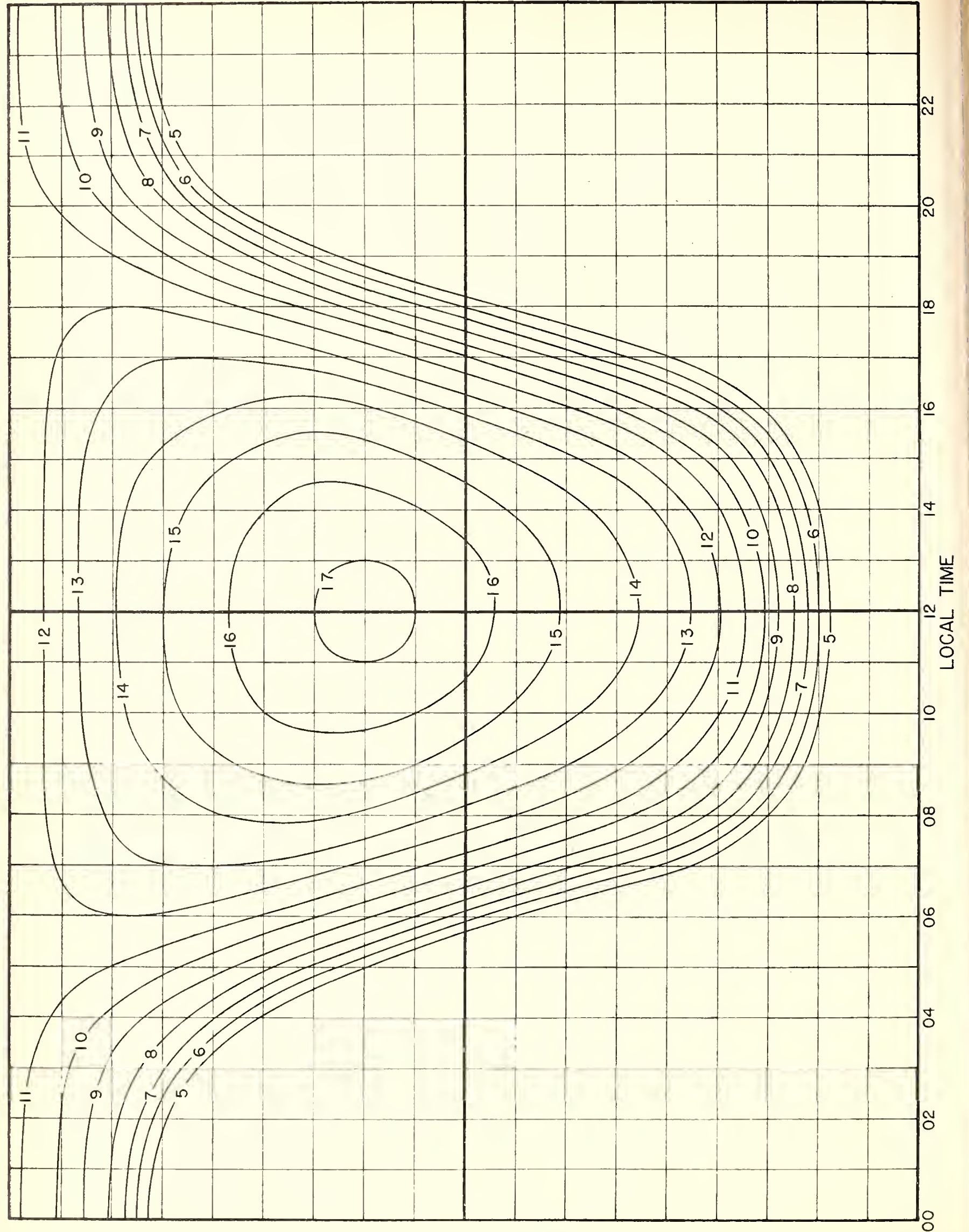

Fig. II. E - LAYER 2000-MUF, IN MC, PREDICTED FOR JUNE, 1945. 


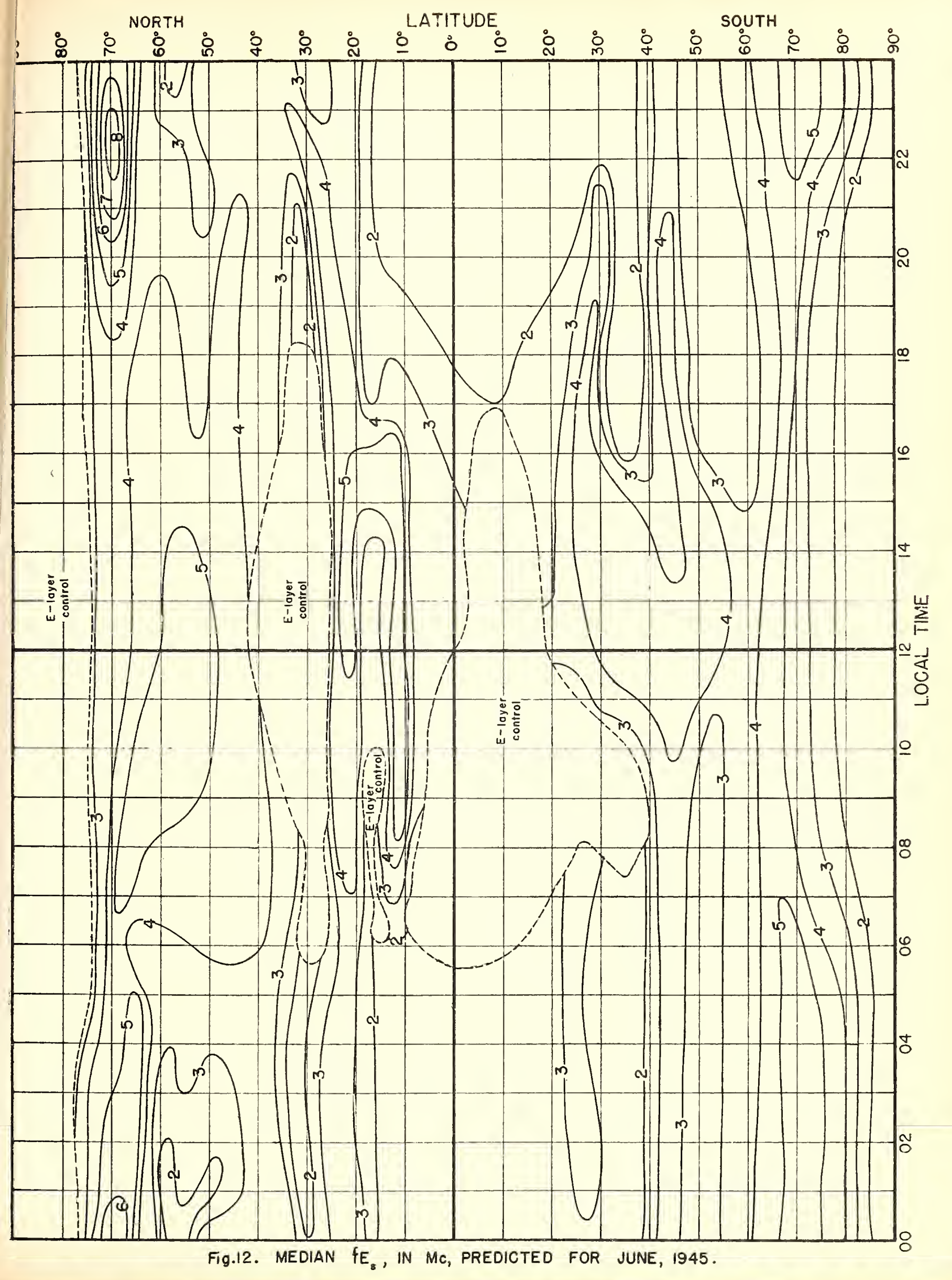


$1 \mathrm{~km}=0.62137$ mile $=0.53961$ nout $\mathrm{mi}$.

1 mile $=1.60935 \mathrm{~km}=0.86836$ nout. $\mathrm{mI}$.

I nout. mi. $=185325 \mathrm{~km}=1.1516 \mathrm{mi}$.
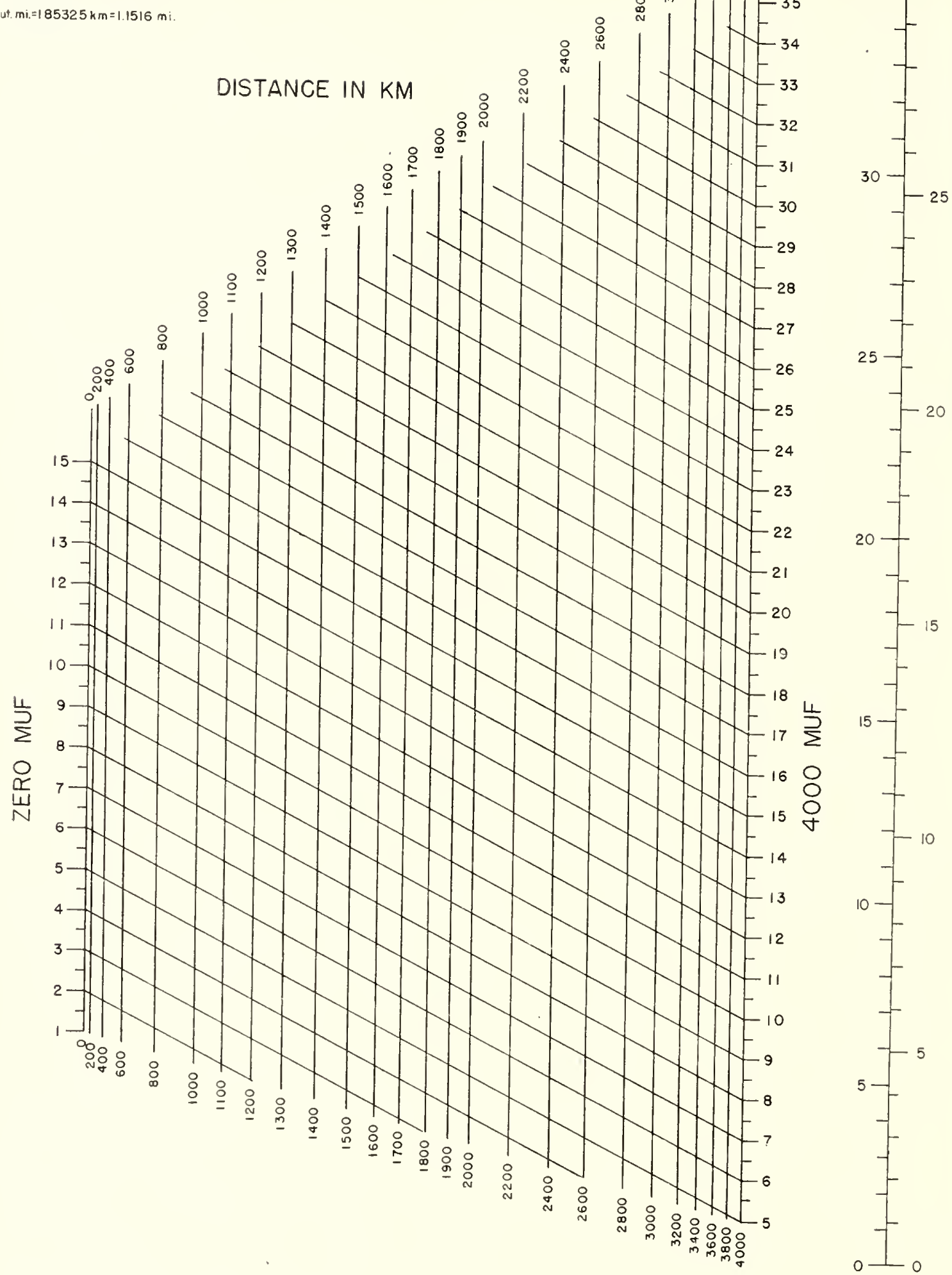

FIG.13. NOMOGRAM FOR TRANSFORMING $F_{2}$-ZERO-MUF AND $F_{2}-4000$-MUF TO EQUIVALENT MAXIMUM USABLE FREQUENCIES AT INTERMEDIATE TRANSMISSION DISTANCES; CONVERSION SCALE FOR OBTAINING OPTIMUM WORKING FREQUENCIES. 
2000-Km E muf,

$\mathrm{MC}$
I $\mathrm{km}=0.62137$ mile $=0.53961$ nout. $\mathrm{mi}$. 1 mile $=1.60935 \mathrm{~km}=0.86836$ naut. $\mathrm{mi}$. I nout. $\mathrm{mi} .=1.85325 \mathrm{~km}=1.1516 \mathrm{mi}$.

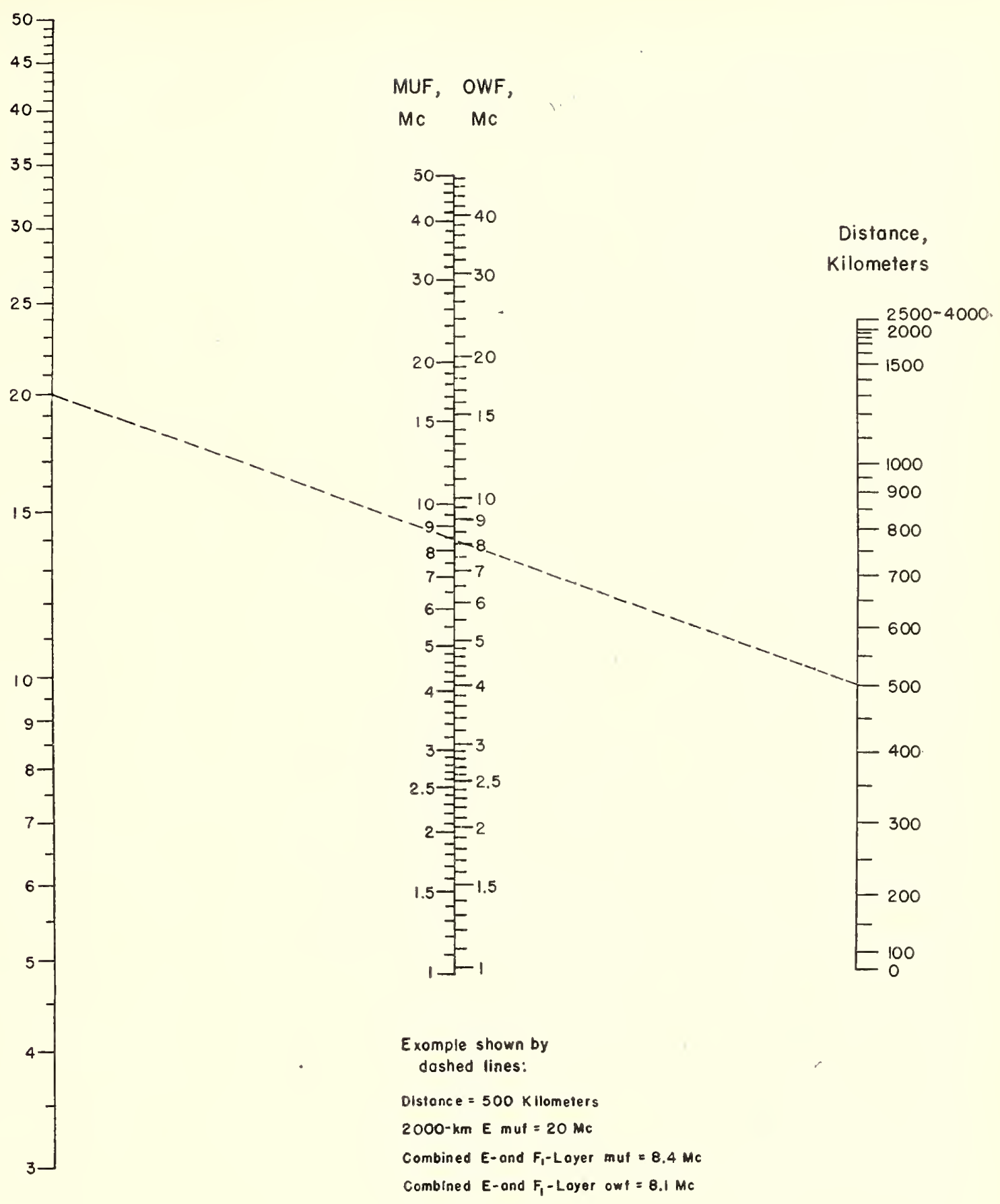

FIG.14. NOMOGRAM FOR TRANSFORMING E-LAYER 2000-MUF TO EQUIVALENT MAXIMUM. USABLE FREQUENCIES AND OPTIMUM WORKING FREQUENCIES DUE TO COMBINED EFFECT OF E LAYER AND F, LAYER AT OTHER TRANSMISSION DISTANCES. 


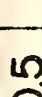

8
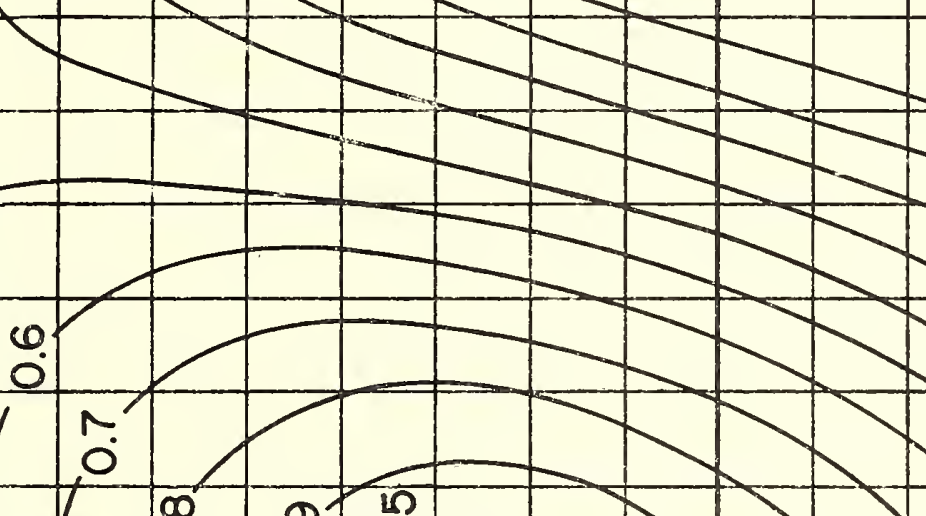

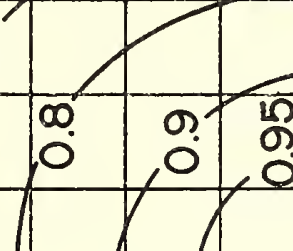
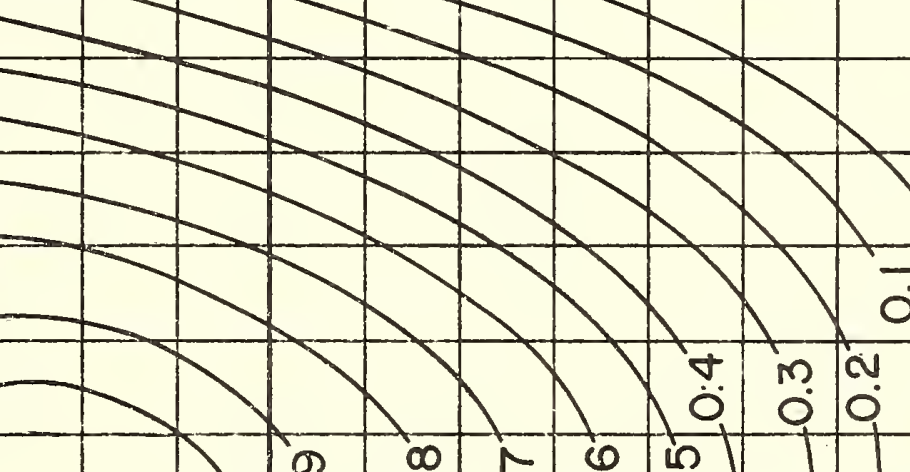

†.
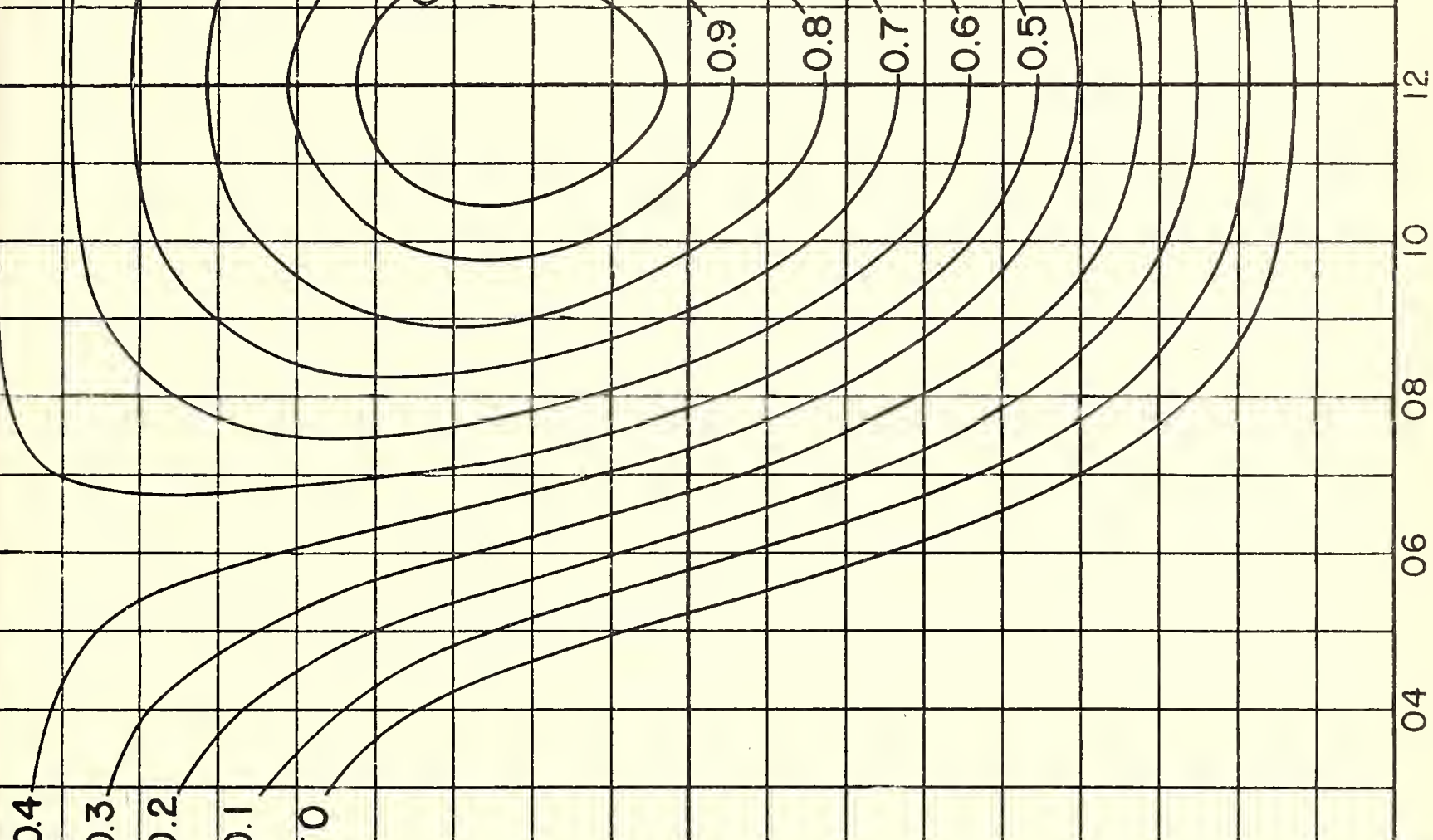

- 0 i 0 

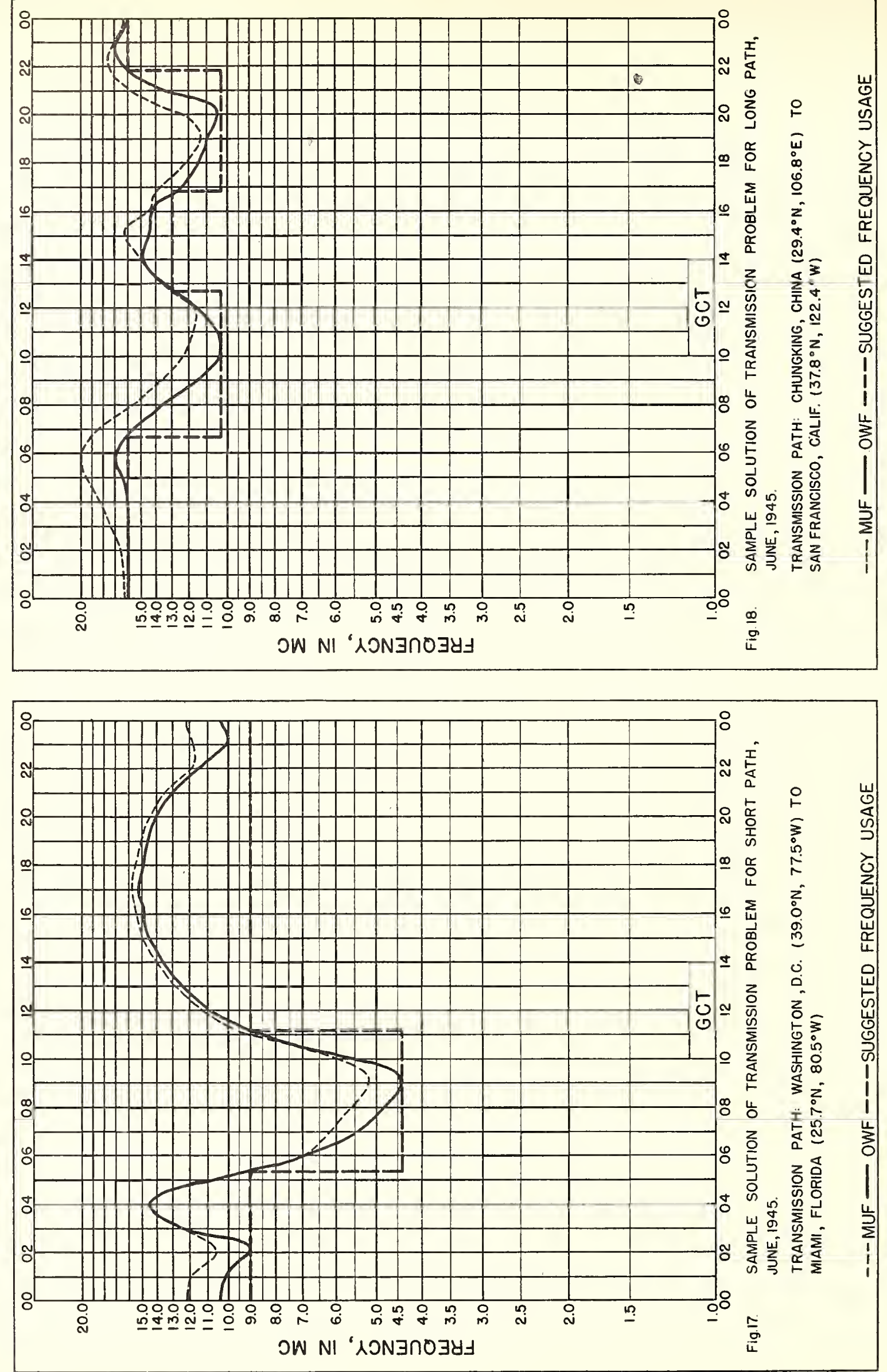


\section{IRPL REPORTS}

Daily:

Telephoned and telegraphed reports of ionospheric, solar, geomagnetic, and radio propagation data from various places.

Radio disturbance warnings.

Semiweekly:

IRPL-J. Radio Propagation Forecast.

Monthly:

IRPL-D. Basic Radio Propagation Predictions-Three months in advance.

IRPL-E. Discontinued.

IRPL-F. Ionospheric Data.

Bimonthly:

IRPL-G. Correlation of D. F. Errors With Ionospheric Conditions.

Quarterly:

IRPL-A. Recommended Frequency Bands for Ships and Aireraft in the Atlantic and Pacific.

IRPL-B. Recommended Frequeney Bands for Submarines in the Pacific.

IRPL-K. Best Radio Frequencies for Aircraft and Ground Stations in the Atlantic.

IRPL-M. (WIMS APPENDIX N) Frequency Guide for Merchant Ships.

Semiannual:

IRPL-H. Frequency Guide for Operating Personnel.

Special Reports, etc.:

IRPL Radio Propagation Handbook, Part 1.

IRPL-C1 through C61. Reports and papers of the International Radio Propagation Conference, 17 April to 5 May 1944.

IRPL-R. Unscheduled reports:

R1. Maximum Usable Frequency Graph Paper.

$\mathrm{R} 2$ and R3. Obsolete.

R4. Methods Used by IRPL for the Prediction of Ionosphere Characteristics and Maximum Usable Frequencies.

R5. Criteria for Ionospheric Storminess.

R6. Experimental studies of ionospheric prop\&gation as appliod to a navigation system.

R7. Further studies of ionospheric propagation as applied to a navigation system.

R8. The Prediction of Usable Frequencies Over a Path of Short or Medium Length, Including the Effects of Es.

R9. An Automatic Instantaneous Indicator of Skip Distance and MUF.

IRPL-T. Reports on Tropospheric Propagation.

T1. Radar Operation and Weather. (Superseded by JANP 101.)

T2. Radio coverage and weather. (Superseded by JANP 102.) 


$$
\text { . }
$$

